\title{
Gap Junctions Linking the Dendritic Network of GABAergic Interneurons in the Hippocampus
}

\author{
Takaichi Fukuda and Toshio Kosaka \\ Department of Anatomy and Neurobiology, Graduate School of Medical Sciences, Kyushu University, \\ Fukuoka 812-8582, Japan
}

The network of GABAergic interneurons connected by chemical synapses is a candidate for the generator of synchronized oscillations in the hippocampus. We present evidence that parvalbumin (PV)-containing GABAergic neurons in the rat hippocampal CA1 region, known to form a network by mutual synaptic contacts, also form another network connected by dendrodendritic gap junctions. Distal dendrites of PV neurons run parallel to the alveus (hippocampal white matter) and establish multiple contacts with one another at the border between the stratum oriens and the alveus. In electron microscopic serial section analysis, gap junctions could be identified clearly at $24 \%$ of these contact sites. A dendrodendritic chemical synapse and a mixed synapse also were found between PV-immunoreactive dendrites. Three-dimensional reconstruction of the dendritic arborization revealed that both PV neurons of the well known vertical type (presumptive basket cells and axoaxonic cells) and those of another horizontal type constitute the dendritic network at the light microscopic level. The extent of dendritic fields of single PV neurons in the lateral direction was $538 \pm 201 \mu \mathrm{m}(n=5)$ in the vertical type and $838 \pm 159$ $\mu \mathrm{m}(n=6)$ in the horizontal type. Our previous and present observations indicate that PV-containing GABAergic neurons in the hippocampus form the dual networks connected by chemical and electrical synapses located at axosomatic and dendrodendritic contact sites, respectively. Gap junctions linking the dendritic network may mediate coherent synaptic inputs to distant interneurons and thereby facilitate the synchronization of oscillatory activities generated in the interneuron network.

Key words: gap junctions; GABA; parvalbumin; hippocampus; electron microscopy; oscillation; synchronization
Recent physiological studies have revealed large-scale synchronous and oscillatory activities such as gamma $(30-80 \mathrm{~Hz})$ (Singer and Gray, 1995; Steriade et al., 1996; Traub et al., 1998) and sharp wave-associated "ripple" (200 Hz) (Ylinen et al., 1995) in mammalian brains. These rhythmic activities are proposed to play important roles in cognition, memory formation, and other higher nervous functions (Gray et al., 1989; Miltner et al., 1999; Rodriguez et al., 1999). The mechanisms underlying these rhythms are still uncertain, but cumulative evidence suggests that a synaptically connected network of GABAergic interneurons is critically involved in generating the oscillatory activities at least in some hippocampal (Soltesz and Deschênes, 1993; Michelson and Wong, 1994; Bragin et al., 1995; Whittington et al., 1995; Ylinen et al., 1995; Traub et al., 1996a) and neocortical (Buhl et al., 1998) cases. Because single hippocampal inhibitory neurons innervate hundreds of principal neurons (Somogyi et al., 1983; Sik et al., 1995; Halasy et al., 1996), oscillations generated in the interneuron network will produce periodic inhibition efficaciously in a large number of targeted neurons, set their timing of discharge inphase, and thereby cause synchronous oscillatory activities in a large population of neurons (Cobb et al., 1995).

\footnotetext{
Received Sept. 24, 1999; revised Nov. 17, 1999; accepted Dec. 3, 1999.

This work was supported by Grants-in-Aid for Exploratory Research (10878150) to T.F., for Scientific Research on Priority Areas (A) (11170242) and for Scientific Research (B) (09480213) to T.K., from The Japanese Ministry of Education, Science, Sports and Culture, and also by a grant from the Ichiro Kanehara Foundation to T.F. We are grateful to Drs. Claus W. Heizmann and Shinobu C. Fujita for providing antibodies.

Correspondence should be addressed to Dr. Takaichi Fukuda at the above address. E-mail: fukuda@a3rd.med.kyushu-u.ac.jp.

Copyright (C) 2000 Society for Neuroscience 0270-6474/00/201519-10\$15.00/0
}

Several physiological (Michelson and Wong, 1994; Ylinen et al., 1995) and computer simulation (Traub, 1995; Skinner et al., 1999) studies have suggested that gap junctions between GABAergic interneurons, if they exist, will facilitate synchronous oscillations. Our previous ultrastructural studies (Kosaka, 1983a,b; Kosaka and Hama, 1985) clearly demonstrated that certain types of hippocampal interneurons, especially those containing a calciumbinding protein parvalbumin (PV) (Katsumaru et al., 1988b), form gap junctions between their dendrites. PV neurons correspond to somatic inhibitory interneurons (Kosaka et al., 1987; Katsumaru et al., 1988a) that target the perisomatic domain of pyramidal cells and possibly regulate the generation of $\mathrm{Na}^{+}$dependent action potentials there (Knowles and Schwartzkroin, 1981; Buhl et al., 1994a; Miles et al., 1996). With the use of a particular combination of enzyme isoforms for GABA synthesis at their synaptic terminals (Fukuda et al., 1998), PV neurons innervate not only pyramidal cells but other PV neurons as well through dense mutual synaptic contacts on their somata and proximal dendrites (Sik et al., 1995; Fukuda et al., 1996). Accordingly, PV neurons can form both dendrodendritic gap junctions and a synaptically connected network, supporting the above hypothesis that gap junctions facilitate synchronous oscillations generated in the interneuron network. However, the gap junctional profiles we previously observed were limited to those formed between vertically oriented dendrites arising from nearby neurons [see Kosaka and Hama (1985), their Fig. 12], suggesting synchrony only in a localized circuit; it remains uncertain how gap junctions are incorporated in a large-scale network and implicated in the long-range synchrony. The present study aims to search for an unrecognized network structure linked by gap junctions, particularly that extends laterally inside the hippocam- 

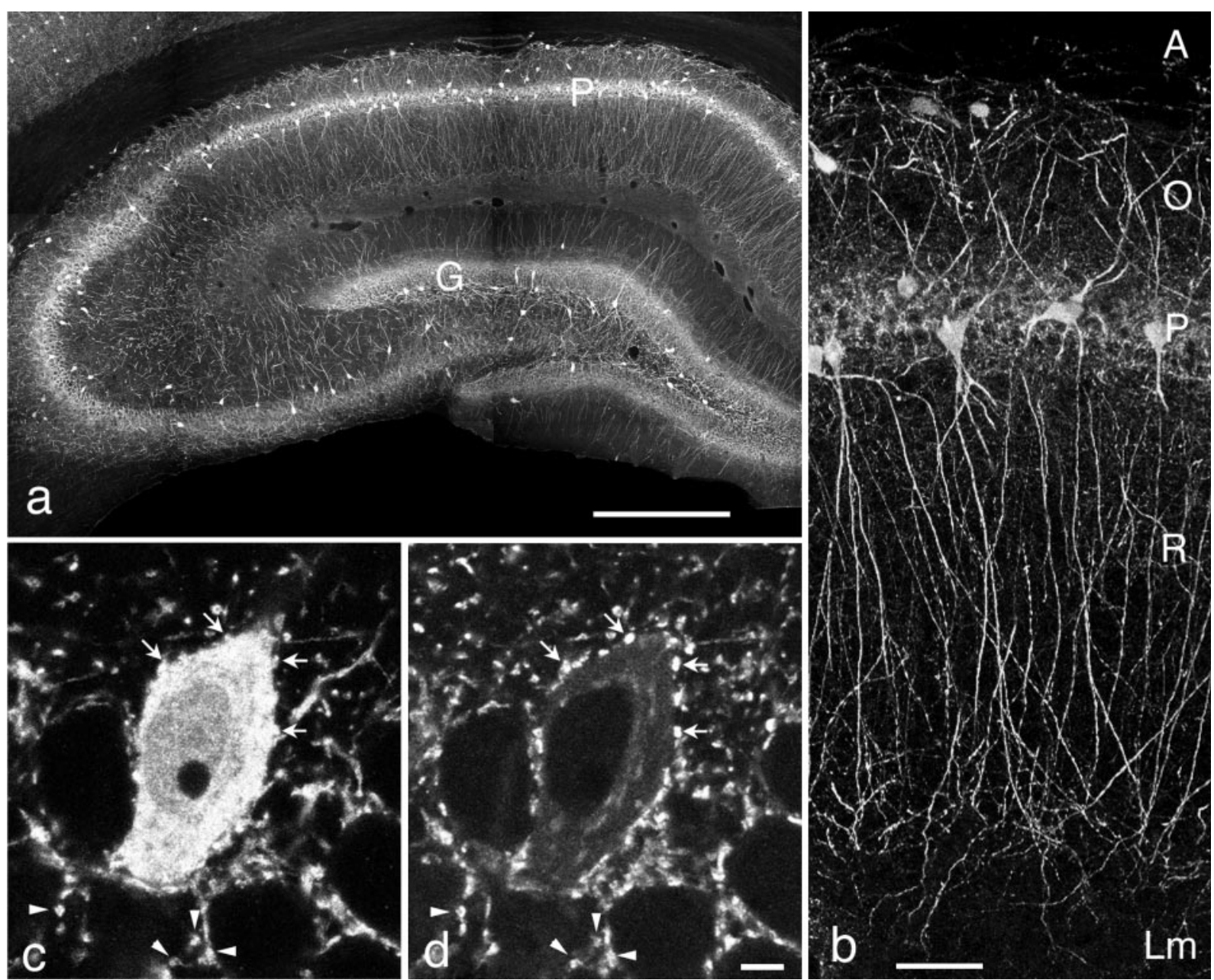

Figure 1. Morphological characteristics of PV neurons viewed in conventionally oriented coronal sections. $a$, A montage of confocal laser-scanning microscopic images. Somata of PV neurons are located mainly in and around the pyramidal cell layer $(P)$ and the granule cell layer $(G)$. Their axon terminals also are distributed in the same layers, causing band-like staining in lower magnification. $b$, PV neurons in the pyramidal cell layer of the CA1 region give rise to dendrites spanning all hippocampal layers. $A$, Alveus; $O$, stratum oriens; $R$, stratum radiatum; $L m$, stratum lacunosum-moleculare. $c$, $d$, Double immunostaining with antibodies against PV $(c)$ and GAD $(d)$. Note multiple PV-containing GAD-immunoreactive (ir) boutons (arrows) abutting on the PV-ir soma. Arrowheads indicate similarly double-labeled boutons, some of which may abut on unstained somata of pyramidal neurons. Scale bars: $a, 0.5 \mathrm{~mm} ; b, 50 \mu \mathrm{m} ; c, d, 5 \mu \mathrm{m}$.

pus, and to shed light on the functional roles of gap junctions in the neural system of the hippocampus.

\section{MATERIALS AND METHODS}

Tissue preparation. Eight male Wistar rats (200-300 gm, 8-12 weeks old) were used in accordance with the institutional guidance for animal welfare. Under deep anesthesia with sodium pentobarbital $(10 \mathrm{mg} / 100 \mathrm{gm}$ body weight, i.p.) the animals were perfused quickly through the ascending aorta with $300 \mathrm{ml}$ of fixative A containing $2.5 \%$ glutaraldehyde and $2 \%$ paraformaldehyde in $0.1 \mathrm{M}$ phosphate buffer (PB) or fixative B containing $4 \%$ paraformaldehyde, $0.1 \%$ glutaraldehyde, and $0.2 \%$ picric acid in the same buffer, $\mathrm{pH}$ 7.2, at room temperature. After cryoprotection and the freezethaw procedure, serial coronal or tangential sections $40-50 \mu \mathrm{m}$ in thickness were cut with a Vibratome (Technical Products, St. Louis, MO). For preparation of tangential sections the hippocampal formation, together with the overlying neocortex, was removed gently from the brainstem and cut transversely into three to four blocks. The surface of the neocortex was glued to the stage, and sectioning was started from the hippocampal surface that originally had faced the thalamus.

Immunocytochemistry. Sections were processed for immunocytochemistry with the use of the free-floating method, as described previously (Fukuda et al., 1996). When fixative A was used, the sections were treated first with $1 \%$ sodium borohydride $\left(\mathrm{NaBH}_{4}\right)$ for 30 min before immunocytochemical procedures (Kosaka et al., 1986). Triton X-100 (0.3\%) was used for confocal laser-scanning microscopy and three-dimensional neuron tracing, but not for immunoelectron microscopy. The primary antibodies used were rabbit polyclonal antibody against rat PV (dilution 1:5000; Kägi et al., 1987), sheep polyclonal antibody S3 (1:2000; Oertel et al., 1981) that recognizes both isoforms of glutamic acid decarboxylase, GAD67 and GAD65, and mouse monoclonal antibody against synaptophysin (1:1000; Obata et al., 1987). For double or triple immunostaining PV was visualized with fluorescein isothiocyanate-conjugated donkey anti-rabbit IgG (1:100; Jackson ImmunoResearch, West Grove, PA), GAD with biotinylated donkey anti-goat IgG (1:500; Jackson ImmunoResearch) followed by lissamine rhodamine-conjugated streptavidin (1:200; Jackson ImmunoResearch), and synaptophysin with Cy5-conjugated donkey anti-mouse IgG (1:200; Jackson ImmunoResearch).

Confocal laser-scanning microscopy. Sections were mounted in Vectashield (Vector Laboratories, Burlingame, CA) and examined with a confocal laser-scanning microscope MRC-1000 (Bio-Rad, Herts, UK) equipped with a krypton-argon ion laser and mounted on a light microscope (Optiphoto, Nikon, Tokyo, Japan), as described (Fukuda et al., 1998). For taking images of higher resolution, a $60 \times$ oil immersion objective (numerical aperture, 1.40; Nikon) was used at $2 \times$ zoom factor. Single laser beams, 488, 568, and $647 \mathrm{~nm}$ in wavelength, were used alternately to collect images for different fluorescent signals, and the bleedthrough was confirmed to be negligible by using the mixer program of the instrument. 

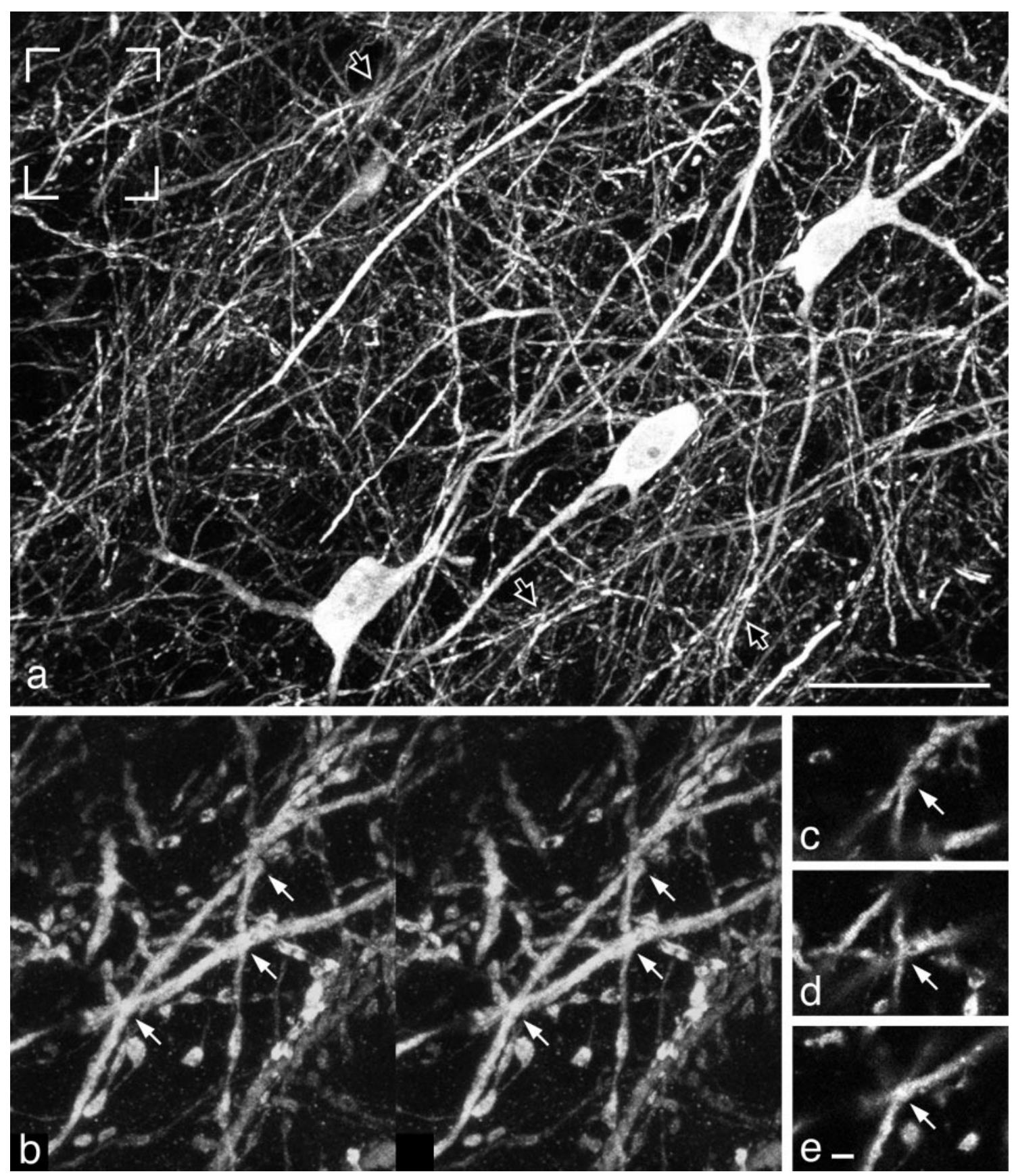

Figure 2. CLSM images in a section cut tangentially along the border between the alveus and the stratum oriens of the CA1 region. $a$, PV-ir dendrites running two-dimensionally within a single 40 - $\mu \mathrm{m}$-thick section form an extremely dense network. Some dendrites appear to be bundled together (open arrows), whereas others cross one another with a fairly wide angle. Four PV-ir somata are of the horizontal type (see Results). $b$, Stereo pair of the enlargement of the framed area in $a$. PV-ir dendrites make multiple contacts with one another, only three of which are indicated by arrows. $c-e$, Single confocal optical images of the three contact sites designated in $b$, suggesting a direct contact between these dendrites. Scale bars: $a, 50 \mu \mathrm{m} ; b-e, 1 \mu \mathrm{m}$.

Electron microscopy. Vibratome sections $(50 \mu \mathrm{m})$ from animals fixed with fixative A were processed for immunocytochemistry as described (Obata et al., 1999), post-fixed with $1 \% \mathrm{OsO}_{4}$ for $1.5 \mathrm{hr}$ on ice, stained en bloc with uranyl acetate, dehydrated, and embedded in Araldite. Serial ultrathin sections $60-70 \mathrm{~nm}$ in thickness were cut from the superficial part of the reembedded specimens, mounted on Formvarcoated single slot grids, lightly stained with uranyl acetate and lead citrate, and examined in a transmission electron microscope (Hitachi H-7100, Tokyo, Japan). For quantitatively analyzing the incidence of gap junctions, two sets of 100 serial ultrathin sections were prepared. Every fifth of the series was examined thoroughly from the upper left corner to lower right of each section. For all of the contact sites between PV-ir dendrites that were encountered, the corresponding profiles in neighboring sections were observed intensively as far as it could be determined whether a gap junction was identifiable at the contact site or not. During the analysis the sample stage was rotated appropriately and then tilted up to $\pm 45^{\circ}$ to visualize the cut ends of apposed junctional membranes clearly, because it was found to be absolutely essential for identifying gap junctions to make the disk-like junctional membranes parallel to the electron beam. Once the specimens were oriented optimally, profiles of closely apposed unit membranes became discernible. When apposed cell membranes were oriented originally parallel to the section surface (perpendicular to the electron beam), they could not become oriented parallel to the electron beam even 

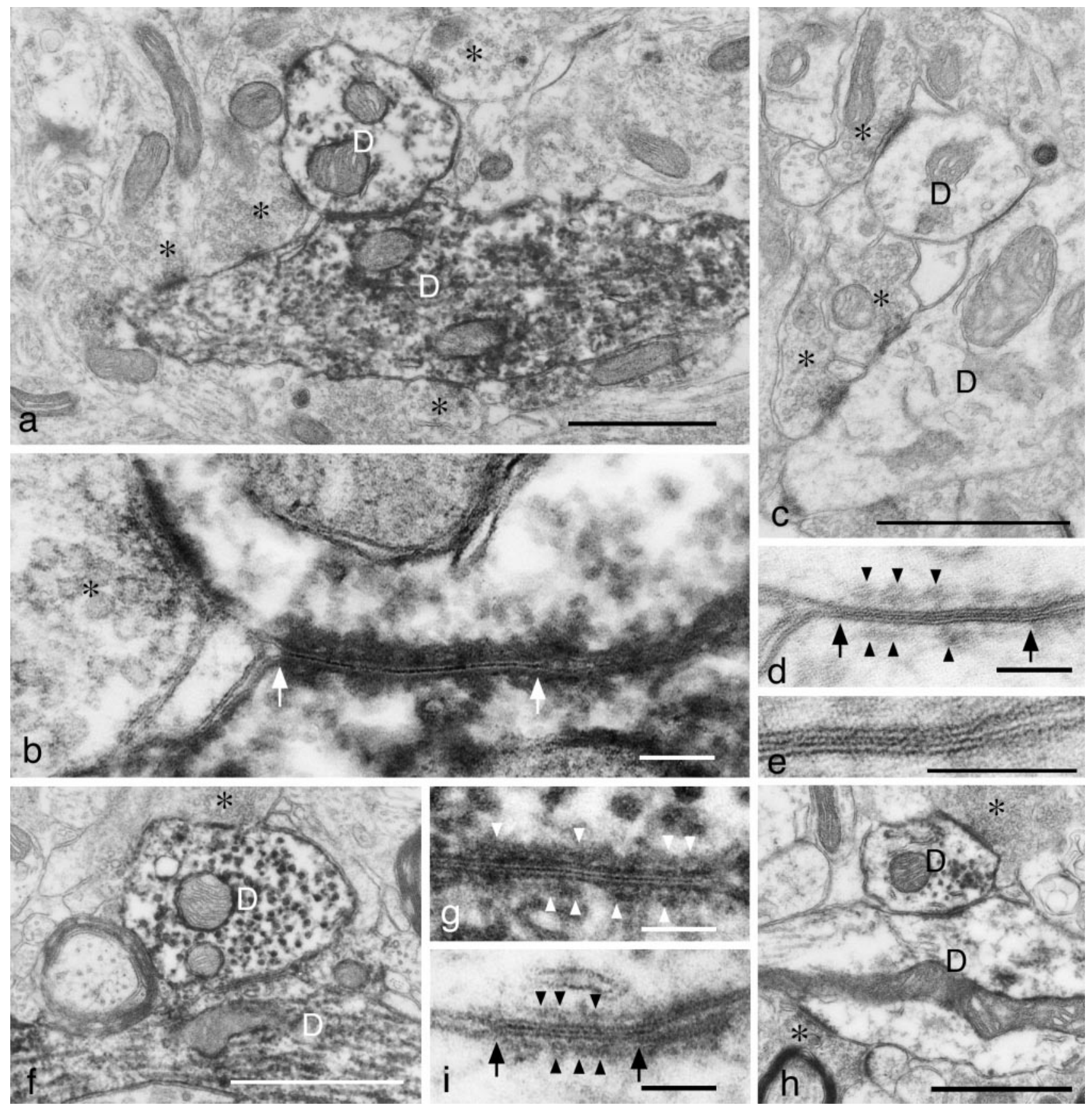

Figure 3. Electron micrographs showing the dendrodendritic gap junctions. $a$, Two PV-ir dendrites $(D)$ receiving multiple presynaptic terminals (asterisks) make direct contact with each other. $b$, Enlargement of the contact site in $a$. A gap junction is formed between the two PV-ir dendrites. Note the close apposition of the plasma membranes of the two contacting cells as demarcated by arrows. A synaptic bouton (asterisk) forming a synapse of asymmetrical type is located in close vicinity to the gap junction. $c$, Electron micrograph of a specimen without immunoreaction, demonstrating a profile similar to $a$. The contacting dendrites $(D)$ receive presynaptic terminals (asterisks). $d$, Enlargement of the contact site in $c$ with the same magnification as in $b, g$, and $i$ to facilitate comparison. Plasma membranes of the two cells are closely apposed, as demarcated by arrows. Note a layer of cytoplasmic semidense material (arrowheads) undercoating either side of the junction, which is characteristic of neuronal gap junctions. $e$, Further enlargement of the contact site in $d$, showing a narrow central gap, $2.7 \mathrm{~nm}$ wide, between the outer leaflets of the apposed unit membranes. $f-i$, Other examples of gap junctions formed between PV-ir dendrites $(D)$. The contact sites in $f$ and $h$ are enlarged in $g$ and $i$, respectively, with the same magnification as in $b$ and $d$. Scale bars: $a, c, f, h, 1 \mu \mathrm{m} ; b, d, e, g, i, 0.1 \mu \mathrm{m}$.

if the sample stage was tilted maximally; such cases were excluded from quantitative analysis.

Neuron tracing. Serial coronal or tangential sections from animals fixed with fixative B were immunostained for PV, colored with diaminobenzidine tetrahydrochloride, enhanced with $\mathrm{OsO}_{4}$, and used for threedimensional reconstruction of the dendritic arborization with the aid of a computer-assisted neuron-tracing system NeuroLucida (MicroBrightField, Colchester, VT). Shrinkage factor was estimated to be 0.80 for coronal sections and 0.84 for tangential sections, respectively, by comparing the size of several sections measured before and after the staining procedures. Reconstructed figures were viewed from different angles by the application software NeuroExplorer (MicroBrightField). 

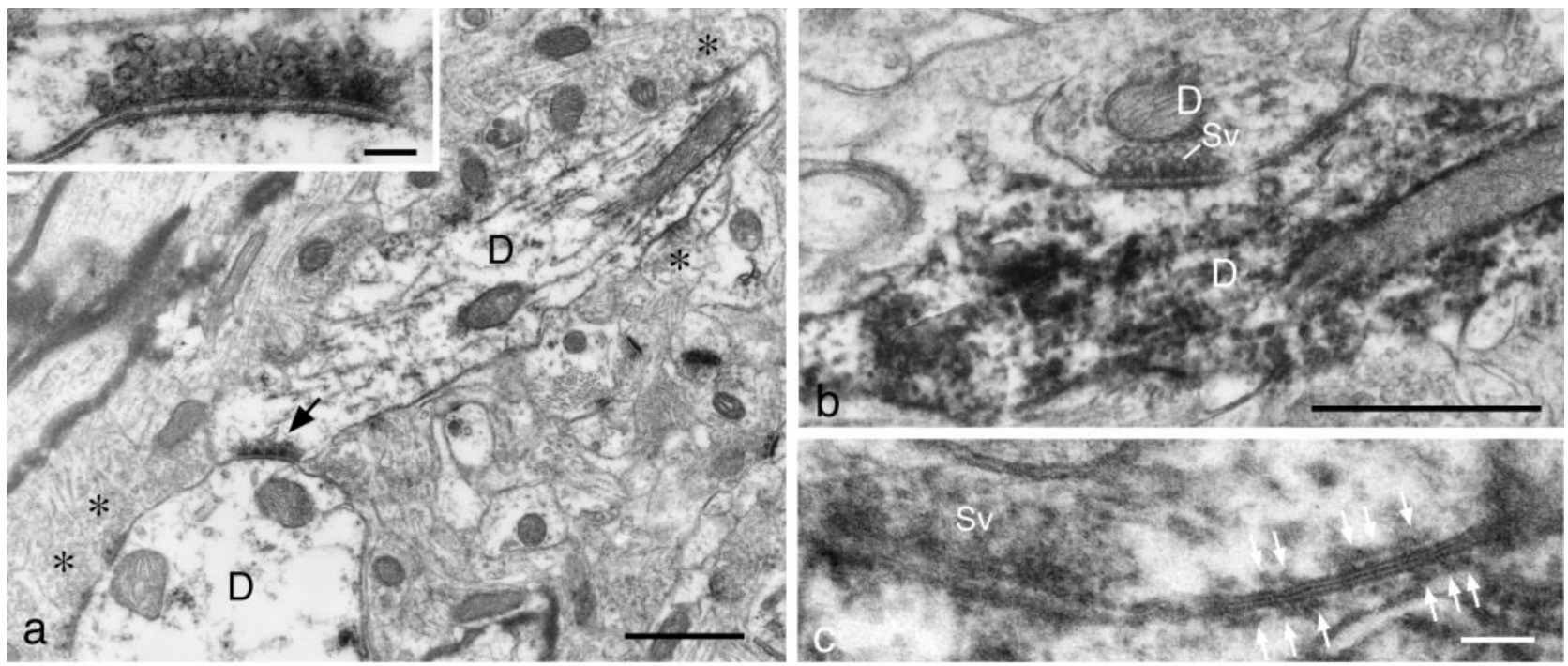

Figure 4. Electron micrographs showing two novel forms of dendrodendritic contacts between PV neurons. $a$, Two PV-ir dendrites $(D)$ receiving multiple presynaptic terminals (asterisks) make direct contact with each other (arrow). Inset, Enlargement of the contact site demonstrating synaptic vesicles, widening of the synaptic cleft, and less prominent thickening of the postsynaptic density; the last feature is consistent to conventional symmetrical synapses, including those formed by PV-ir axon terminals. $b, c$, Serial ultrathin sections with different magnifications demonstrating that two PV-ir dendrites $(D)$, receiving multiple presynaptic terminals (data not shown in these sections), establish a mixed type of synapse between each other. Synaptic vesicles $(S v)$ accumulate in one side of the contact as in $a$, but in this case the gap junction can be identified in line with the chemical synapse in $c$. Note a layer of cytoplasmic semidense material (arrows) undercoating gap junction as in Fig. $3 d, g, i$. Scale bars: $a, b, 1 \mu \mathrm{m} ;$ Inset in $a, c, 0.1 \mu \mathrm{m}$.

\section{RESULTS}

\section{Dendritic network of PV neurons revealed by tangentially oriented slices}

In usual coronal or sagittal sections the somata of PV-containing neurons are observed mainly in and around the pyramidal cell layer (Fig. 1a) with their dendrites spanning all hippocampal layers, giving each neuron a vertical appearance (Fig. 1b). Double immunofluorescently stained sections show that PV neurons establish GABAergic synaptic contacts with somata of both pyramidal cells and other PV neurons (Fig. 1c,d), indicating mutual perisomatic synaptic contacts between PV neurons just as observed in the mouse hippocampus (Fukuda et al., 1996). To reveal a structure that extends laterally inside the hippocampus, we prepared a series of sections cut tangentially to the alveus (hippocampal white matter). In such series we found a dense network of PV-immunoreactive (-ir) dendrites in the most basal part of the hippocampus proper (Fig. $2 a$ ), i.e., at the border between the stratum oriens and the alveus. Numerous PV-ir dendrites spread out within a single 40 - $\mu$ m-thick tangential section, meaning that they were oriented almost two-dimensionally and parallel to the cutting direction, namely to the alveus.

In the high-resolution confocal laser-scanning microscopy (CLSM), PV-ir dendrites in the network appeared to make multiple contacts with one another. This is illustrated in both the stereo-paired (Fig. 2b) and single confocal images (Fig. 2c-e). Such a dense network of PV-ir dendrites with possible mutual contact sites was not a rare profile but was seen ubiquitously all along the border between the stratum oriens and the alveus in the entire CA1 region from the septal to temporal end of the hippocampus.

\section{Ultrastructural identification of gap junctions}

We further investigated by electron microscopy whether these presumable contact sites really have some specialized ultrastructures (Fig. 3). PV-ir dendrites in the oriens/alveus border fre- quently made direct contact with other PV-ir dendrites (Fig. $3 a$, $f, h)$, and in some cases gap junctions could be identified there clearly (Fig. 3b, g, i). Characteristic profiles of neuronal gap junctions were confirmed in more detail by observing similar dendritic contacts in specimens not treated for immunostaining (Fig. $3 c-e$ ). The outer leaflets of plasma membranes of the two contacting dendrites were closely apposed, with a narrow gap between them (Fig. 3e), although in immunolabeled specimens the gap usually was occluded with dense materials, perhaps the immunoreaction products. Another characteristic feature of neuronal gap junctions was a semidense material undercoating the junctional membranes (Fig. $3 d, g, i$ ), which was not observed in glial gap junctions (Sotelo and Korn, 1978).

Although unambiguous profiles of gap junctions were encountered repeatedly, careful examination revealed that gap junctions were not always formed between directly contacting dendrites of PV neurons. So we tried to evaluate the incidence of gap junctions between PV-ir dendrites by systematically and quantitatively observing all of the contact sites located in two series of 100 consecutive ultrathin sections. Six contact sites (24\%) of 25, including one in the mixed synapse (see below), could be identified convincingly as gap junctions, whereas eight contact sites showed no specialization, one site formed dendrodendritic chemical synapse (see below), and the remaining 10 sites showed ambiguous profiles that were obscured by dense immunoreaction products. It was concluded that at least a quarter of contact sites between PV-ir dendrites at the oriens/alveus border formed gap junctions. In contrast to the frequent occurrence of gap junctions between PV-ir dendrites, we encountered no gap junctions between PV-negative neuronal profiles, although we did not observe them systematically and therefore might have underestimated the latter.

In the course of the serial section analysis, two novel types of connections were observed between PV-ir dendrites. One was a dendrodendritic synapse ( $n=1$ of 25 contact sites; Fig. $4 a$ ), and 
vertical type
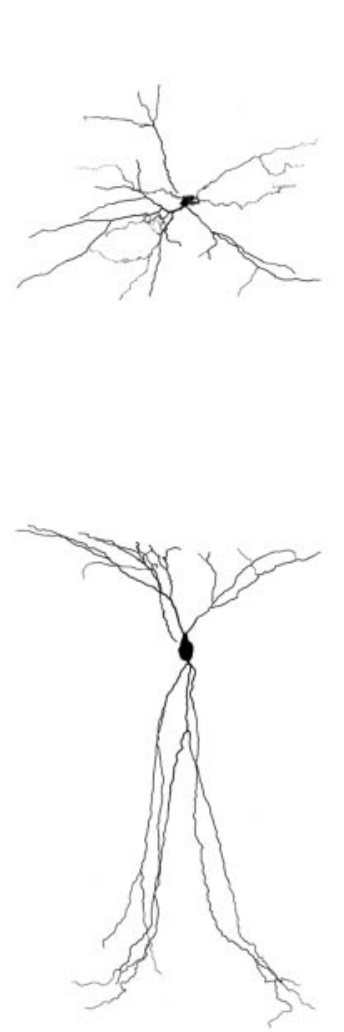

Figure 5. Comparison of the reconstructed dendritic arborization of PV neurons between the vertical type (left) and the horizontal type (right), viewed in two directions (top, top view; down, front view) with the use of a computer-assisted neuron tracing system. The top and front views are of the same cell in each type and are aligned.

the other was a mixed synapse establishing both a chemical synapse and a gap junction side by side $(n=1$ of 25 contact sites; Fig. $4 b, c)$. By observing neighboring consecutive sections, we found that in each case synaptic vesicles were located only in one side of the synaptic connections; i.e., neither of these two contacts formed reciprocal synapses. The existence of the dendrodendritic synaptic contact indicates that dendrites of PV neurons can communicate occasionally with each other via chemical synapses.

PV-ir dendritic membranes received multiple synaptic contacts, most of which were of the asymmetrical type (see Fig. 3). This was in good accordance with CLSM observations of the tripleimmunostained sections (see Fig. $6 a$ ) showing that PV-ir dendrites are surrounded by numerous synaptophysin-positive/ glutamic acid decarboxylase (GAD)-negative boutons, a majority of which are thought to correspond to boutons making asymmetrical synapses (see Fig. 3a). Although no physiological data are available now, this ultrastructural arrangement leads us to speculate that the changes in postsynaptic membrane potentials in PV-ir dendrites, at least those induced by synaptic inputs near gap junctions, may be transmitted directly from one dendrite to another through gap junctions.

\section{Three-dimensional reconstruction of the PV neurons that constitute the network}

Finally, we examined the origins of the dendrites forming the network. We made a detailed three-dimensional analysis of the dendritic arborization by using a computer-assisted neuron trac- ing system (Fig. 5). In specimens prepared for immunoelectron microscopy, the permeation of antibodies into sections was restricted greatly, and only short segments of dendrites located near the section surface were immunostained. Therefore, it was very difficult to trace dendrites from the sites of ultrastructurally identified gap junctions all the way back to their parent somata in our trials of the correlated light and electron microscopy. The following analysis was based on light microscopic observations and our intent to know the possible constituents of the dendritic network.

Dendrites arising from PV neurons of the well known vertical type, the somata of which were located in and around the pyramidal cell layer, were followed in serial coronal sections. It was found that all of the basal dendrites ran obliquely in the stratum oriens (see Figs. $1 b, 5,6 b$ ), gradually changed direction more horizontally before reaching the oriens/alveus border, and finally became oriented almost parallel to the alveus, joining the network there (Fig. 5, left panel). Dendrodendritic contacts often were observed along the horizontal part of the dendrites. By viewing the reconstructed dendritic trees from the top side just as if they had been viewed in tangential sections, we estimated the size of the dendritic field of these conventional PV neurons along the oriens/alveus border to be $538 \pm 201 \mu \mathrm{m}(n=5$; ranging from 377 to $875 \mu \mathrm{m}$ ) in the largest diameter.

Besides the above-mentioned vertical type, we noted PV neurons of a horizontal type, which have not been well described previously (Katsumaru et al., 1988a). They were located in the stratum oriens, most frequently at the border to the alveus. In coronal sections long dendrites arising from these cells ran along the alveus (Fig. 6b). In tangential sections their long dendrites appeared to extend in all directions parallel to the oriens/alveus border (see Figs. $2 a, 6 c$ ). Multiple dendrodendritic contacts were observed along the dendrites, just as seen in the vertical type. Three-dimensional reconstructions revealed that the dendritic field of the horizontal PV neurons along the oriens/alveus border reached $838 \pm 159 \mu \mathrm{m}(n=6$; ranging from 689 to $1057 \mu \mathrm{m})$ in the largest diameter (see Fig. 5, right panel). The reconstructions also showed one or two additional dendrites ascending into the pyramidal cell layer (see Fig. 5). Some, but not all, of the horizontal PV neurons received dense PV-ir GABAergic terminals on their somata and proximal dendrites (Fig. $6 d, e$ ), a feature common to the conventional vertical type (see Fig. $1 c, d$ ). Similar profiles also were observed in animals in which extrinsic septohippocampal PV-ir fibers had been removed by bilateral transection of the fimbria fornix (our unpublished observations), indicating that at least a part of the PV-ir terminals on the horizontal type is thought to be derived from intrinsic PV neurons.

\section{DISCUSSION}

The findings are summarized schematically in Figure 7. PV-ir GABAergic neurons form a dense network of horizontally oriented long dendrites that make direct contact with one another at multiple sites. Both the well known vertical type, corresponding to somatic inhibitory cells, and another horizontal type constitute the network. Ultrastructural profiles of gap junctions could be observed in at least a quarter of the contact sites in the network, although it remains undetermined how these two neuronal types are involved in gap junctional coupling (see below). The dendritic network at the oriens/alveus border appears to be continuous all along the septotemporal (longitudinal) axis of the hippocampus. Moreover, PV neurons in the CA3 region also form a dendritic network similar to and continuous with the network in the CA1 region. Taken together, it is likely that a large population of $\mathrm{PV}$-ir 

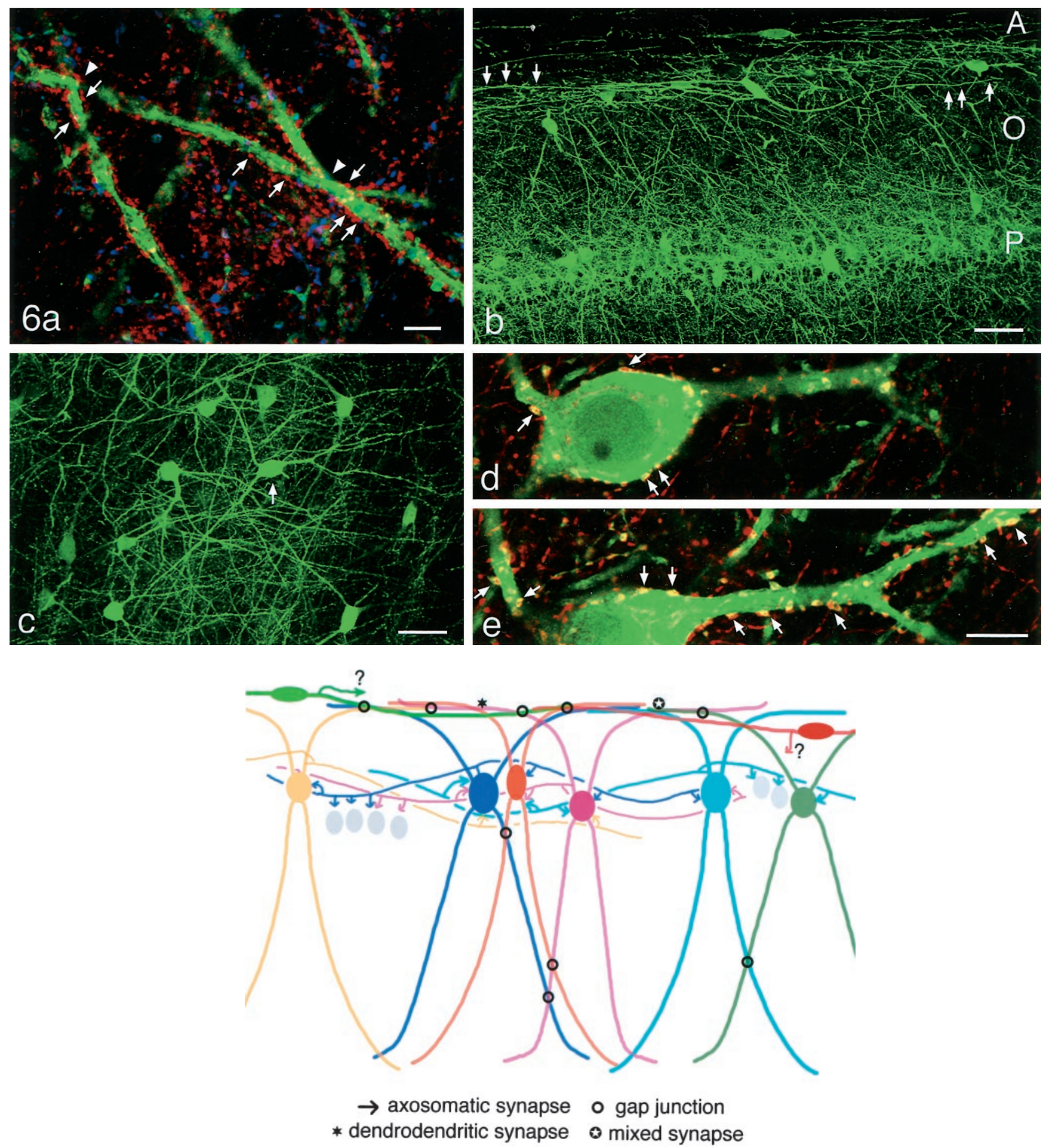

Figure 6. Top. CLSM images showing several morphological aspects of PV-ir neurons viewed in tangential $(a, c-e)$ and coronal $(b)$ sections. $a$, Triple-immunostained section at the border between the stratum oriens and the alveus. PV-ir dendrites (green) receive numerous synaptophysin (red)-positive and GAD (blue)-negative boutons (arrows). The mutual contact sites in dendrites are shown by arrowheads. $b$, A PV neuron of the horizontal type (arrow) located at the border between the stratum oriens $(O)$ and the alveus $(A)$ gives rise to long dendrites (arrowheads) along the border. The stratum oriens contains many obliquely running dendrites originating from PV-ir somata located in and around the stratum pyramidale $(P)$. $c$, Dendrites of horizontal PV neurons extend in all directions from their somata along the horizontal plane. $d, e$, Enlargement of the PV-ir neuron, indicated by an arrow in $c$, double-immunostained with antibodies against PV (green) and GAD (red). CLSM images in $d$ and $e$ were taken at different depths from the section surface. Note numerous PV-containing GABAergic boutons (arrows) abutting on the soma and proximal dendrites. Scale bars: $a, 5 \mu \mathrm{m} ; b, c, 50 \mu \mathrm{m} ; d, e, 10 \mu \mathrm{m}$.

Figure 7. Bottom. A schematic drawing representing the dual networks of hippocampal PV neurons connected by chemical and electrical synapses. PV neurons are shown in color, whereas pyramidal cell somata are depicted as gray ovals. Frequent occurrence of gap junctions between horizontally oriented dendrites (top of the figure) was confirmed by quantitative electron microscopic analysis, but it remains unknown whether both or either of the two neuronal types (vertical and horizontal) actually forms gap junctions there. See Discussion for details. 
neurons in the hippocampus proper forms the dendritic network at both the apical (Katsumaru et al., 1988b) and basal (present observations) contact sites. Because PV neurons (Sik et al., 1995; Fukuda et al., 1996) and the corresponding somatic inhibitory neurons (Cobb et al., 1997) also form a network connected by mutual perisomatic synapses and because the extent of their axonal fields is similar in size to that of the dendritic fields shown here (Buhl et al., 1994b; Sik et al., 1995; Halasy et al., 1996), PV neurons in the hippocampus appear to form the dual networks mediated by chemical and electrical synapses located at axosomatic and dendrodendritic contact sites, respectively.

\section{Identification of neuronal gap junctions}

In mammalian brains unambiguous ultrastructural evidence for the existence of neuronal gap junctions has been demonstrated only in very limited areas (Brightman and Reese, 1969; Pinching and Powell, 1971; Sloper, 1972; Sotelo et al., 1974; Kosaka and Hama, 1985) (for review, see Sotelo and Korn, 1978), and works elucidating the functional significance of neuronal gap junctions are rare (Llinás et al., 1974; De Zeeuw et al., 1996). In the present study gap junctions could be observed clearly in immunocytochemically identified neurons by careful preparation of the specimens, using a high concentration of glutaraldehyde for fixation, and by detailed electron microscopic observations. Incidence of gap junctions was estimated further by serial ultrathin section analysis, and their distribution was correlated to the large-scale network structure of dendrites that arise from neurons constituting a potential oscillation generator. Although we had no physiological data, the present results will provide an anatomical basis for understanding functional aspects of neuronal gap junctions in mammalian cortical circuits.

\section{Dendrodendritic chemical synapse and mixed synapse}

Two additional types of dendritic contacts, dendrodendritic chemical synapse and mixed synapse, were noted between PV neurons. Although not described earlier in the hippocampus, similar structures already have been demonstrated between dendrites of nonpyramidal neurons in the neocortex (Sloper, 1972; Sloper and Powell, 1978). Only one profile was found for each type here, but this might be an underestimation because immunoreaction products frequently obscured ultrastructural details. In each type synaptic vesicles accumulated in dendritic shafts. The localization of presynaptic sites in dendritic shafts resembles that in mitral cell dendrites in the olfactory bulb (Rall et al., 1966) but is contrasted with the synaptic glomeruli in the thalamic nuclei (Rafols and Valverde, 1973) and the gemmules of granule cells in the olfactory bulb (Price and Powell, 1970); in the latter two structures spine-like presynaptic sites in the dendrites are segregated from dendritic shafts by intervening thin necks. Presynaptic dendrites of mitral cells are activated by spikes propagated along the dendritic shafts, whereas activation of presynaptic spine-like structures is thought to result from local excitatory synaptic inputs inside the segregated structures (Jahr and Nicoll, 1982). Further physiological studies are needed to determine whether transmitter release from PV-ir dendritic shafts is induced by possible dendritic spikes as in mitral cells or by local inputs. As to the dendrodendritic mixed synapse, although similar profiles were described in the neocortex (Sloper, 1972; Sloper and Powell, 1978), little is known about its functional role in vertebrates.

\section{Horizontal PV neurons}

PV neurons of a horizontal type were noticed in tangential sections. Although we could not determine their axonal targets, part of them may correspond to the "oriens/alveus interneurons" sending axons in the pyramidal cell layer (Lacaille et al., 1987), because there is some resemblance between the two populations both in the dendritic arborization pattern (many horizontal dendrites with additional one or two ascending processes) and in the axonal ramification pattern in the pyramidal cell layer. Alternatively, they may belong to so-called O-LM interneurons that selectively innervate the stratum lacunosum-moleculare (McBain et al., 1994; Sik et al., 1995). However, this does not seem to be the case, because PV-ir terminals are observed only rarely in that layer. Dense PV-ir boutons abutting on some horizontal PV neurons suggest another possibility that some of them innervate one another. Because axons of the vertical type reconstructed in vivo do not enter the alveus/oriens border (Sik et al., 1995), PV-ir boutons on the horizontal type appear to be derived from sources other than the vertical type. In any case, the fact that some horizontal PV neurons are densely innervated by other PV neurons suggests that part of this type also joins the GABAergic network linked by synaptic contacts and might be involved in the generation of oscillatory/synchronous activity.

\section{Origins of gap junction-forming dendrites}

It is important to emphasize that the present ultrastructural results did not demonstrate directly the parent somata to which gap junction-coupled dendrites could be traced. This was attributable to the mutually exclusive experimental conditions; i.e., fair preservation of tissues was an essential prerequisite to the ultrastructural identification of gap junctions, whereas it greatly reduced the permeation of antibodies, leading to the labeling of only short dendritic segments. On the other hand, dendrodendritic contact sites at the light microscopic level were located mainly in the distal dendrites, several hundred micrometers apart from their somata. Accordingly, it remains unknown whether the dendrodendritic gap junctions in the oriens/alveus border include junctions only between vertical cells or between horizontal cells or are between both horizontal and vertical cells. However, as to the possibility of junctions between vertical cells, we previously observed gap junctions between PV-ir vertical dendrites in the stratum radiatum (Katsumaru et al., 1988b), which correspond most probably to apical dendrites of the vertical type. This indicates that vertical PV neurons constantly express proteins to form gap junctions, raising the possibility that they also form gap junctions between their dendrites elsewhere, e.g., near the alveus/ oriens border. Because multiple dendrodendritic contacts also were observed along dendrites of horizontal PV neurons at the light microscopic level, attempts should be continued to ensure the existence of dendritic gap junctions in both types of PV neuron and to establish "the dendrodendritic connectivity" between PV neurons.

\section{Functional implications of gap junction-mediated network}

Because transmembrane proteins constructing gap junctions are permeable to small molecules, gap junctions formed between excitable cells can mediate the electrical coupling of the cells, leading to synchronous activity of the interconnected cell population. In the present study gap junctions were found between dendrites of hippocampal PV neurons. PV neurons form a GABAergic synapse-mediated network with both pyramidal cells and other PV neurons. This synaptically connected network has been assumed to be an oscillation generator (Whittington et al., 1995; Traub et al., 1996a). Recently, it has been shown that 
excitatory connections from pyramidal cells to interneurons will reinforce the synchronous gamma oscillations (Traub et al., 1996b). Importantly, the border between the stratum oriens and the alveus, where the gap junction-mediated horizontal dendritic network is located, is the terminal region of axon collaterals from CA1 pyramidal neurons. In fact, paired intracellular recordings revealed that single pyramidal cells elicit EPSPs in postsynaptic interneurons located at the oriens/alveus border (Lacaille et al., 1987; Ali and Thomson, 1998). Therefore, numerous asymmetrical synapses abutting on PV-ir horizontal dendrites are thought to be derived mainly from pyramidal cell axons. If these inputs are transmitted through gap junctions and are shared as coherent inputs between network-forming PV neurons, they will greatly facilitate the synchronization of oscillatory activities generated in the interneuron network. Very recently, simultaneous recordings from pairs of fast-spiking cells in the neocortex revealed a high occurrence of electrical coupling among them (Galarreta and Hestrin, 1999; Gibson et al., 1999). These neurons were reported to be PV-immunoreactive in most cases and also were interconnected by GABAergic synapses. Therefore, the dual networks of PV-containing GABAergic neurons that we found in the hippocampus appear to be common to several cortical regions.

The large size of dendritic fields $(500-800 \mu \mathrm{m}$, on average) suggests that coherent inputs might be shared between PV-ir dendrites arising from spatially distant somata. This partially may explain the mechanisms of long-range synchrony observed in vivo. Moreover, so long as it is considered anatomically, the entire network of horizontally oriented dendrites that are linked by multiple gap junctions will cover a broader area, several millimeters wide. Interestingly, the present data revealed that some dendrites of PV neurons have a presynaptic nature in their morphological features (see Fig. 4). Based on the high probability of synaptic transmission between presynaptic pyramidal cells and postsynaptic somatic inhibitory neurons (Gulyás et al., 1993), a computational modeling study (Traub and Miles, 1995) suggested the occurrence of active propagation of signals along the dendrites of hippocampal somatic inhibitory neurons. Possible active conductance along PV-ir dendrites might strengthen the transmission of coherent signals and reinforce the synchronous activity in a wider area.

\section{REFERENCES}

Ali AB, Thomson AM (1998) Facilitating pyramid to horizontal oriensalveus interneurone inputs: dual intracellular recordings in slices of rat hippocampus. J Physiol (Lond) 507:185-199.

Bragin A, Jandó G, Nádasdy Z, Hetke J, Wise K, Buzsáki G (1995) Gamma $(40-100 \mathrm{~Hz})$ oscillation in the hippocampus of the behaving rat. J Neurosci 15:47-60.

Brightman MW, Reese TS (1969) Junctions between intimately apposed cell membranes in the vertebrate brain. J Cell Biol 40:648-677.

Buhl EH, Halasy K, Somogyi P (1994a) Diverse sources of hippocampal unitary inhibitory postsynaptic potentials and the number of synaptic release sites. Nature 368:823-828.

Buhl EH, Han Z-S, Lörinczi Z, Stezhka VV, Karnup SV, Somogyi P (1994b) Physiological properties of anatomically identified axo-axonic cells in the rat hippocampus. J Neurophysiol 71:1289-1307.

Buhl EH, Tamás G, Fisahn A (1998) Cholinergic activation and tonic excitation induce persistent gamma oscillations in mouse somatosensory cortex in vitro. J Physiol (Lond) 513:117-126.

Cobb SR, Buhl EH, Halasy K, Paulsen O, Somogyi P (1995) Synchronization of neuronal activity in hippocampus by individual GABAergic interneurons. Nature 378:75-78.

Cobb SR, Halasy K, Vida I, Nyiri G, Tamás G, Buhl EH, Somogyi P (1997) Synaptic effects of identified interneurons innervating both interneurons and pyramidal cells in the rat hippocampus. Neuroscience 79:629-648.
De Zeeuw CI, Lang EJ, Sugihara I, Ruigrok TJH, Eisenman LM, Mugnaini E, Llinás R (1996) Morphological correlates of bilateral synchrony in the rat cerebellar cortex. J Neurosci 16:3412-3426.

Fukuda T, Aika Y, Heizmann CW, Kosaka T (1996) Dense GABAergic input on somata of parvalbumin-immunoreactive GABAergic neurons in the hippocampus of the mouse. Neurosci Res 26:181-194.

Fukuda T, Aika Y, Heizmann CW, Kosaka T (1998) GABAergic axon terminals at perisomatic and dendritic inhibitory sites show different immunoreactivities against two GAD isoforms, GAD67 and GAD65, in the mouse hippocampus: a digitized quantitative analysis. J Comp Neurol 395:177-194.

Galarreta M, Hestrin S (1999) A network of fast-spiking cells in the neocortex connected by electrical synapses. Nature 402:72-75.

Gibson JR, Beierlein M, Connors BW (1999) Two networks of electrically coupled inhibitory neurons in neocortex. Nature 402:75-79.

Gray CM, König P, Engel AK, Singer W (1989) Oscillatory responses in cat visual cortex exhibit inter-columnar synchronization which reflects global stimulus properties. Nature 338:334-337.

Gulyás AI, Miles R, Sik A, Tóth K, Tamamaki N, Freund TF (1993) Hippocampal pyramidal cells excite inhibitory neurons through a single release site. Nature 366:683-687.

Halasy K, Buhl EH, Lörinczi Z, Tamás G, Somogyi P (1996) Synaptic target selectivity and input of GABAergic basket and bistratified interneurons in the CA1 area of the rat hippocampus. Hippocampus 6:306-329.

Jahr CE, Nicoll RA (1982) An intracellular analysis of dendrodendritic inhibition in the turtle in vitro olfactory bulb. J Physiol (Lond) 326:213-234.

Kägi U, Berchtold MW, Heizmann CW (1987) $\mathrm{Ca}^{2+}$-binding parvalbumin in rat testis: characterization, localization, and expression during development. J Biol Chem 262:7314-7320.

Katsumaru H, Kosaka T, Heizmann CW, Hama K (1988a) Immunocytochemical study of GABAergic neurons containing the calciumbinding protein parvalbumin in the rat hippocampus. Exp Brain Res 72:347-362 .

Katsumaru H, Kosaka T, Heizmann CW, Hama K (1988b) Gap junctions on GABAergic neurons containing the calcium-binding protein parvalbumin in the rat hippocampus (CA1 region). Exp Brain Res 72:363-370.

Knowles WD, Schwartzkroin PA (1981) Local circuit synaptic interactions in hippocampal brain slices. J Neurosci 1:318-322.

Kosaka T (1983a) Gap junctions between nonpyramidal cell dendrites in the rat hippocampus (CA1 and CA3 regions). Brain Res 271:157-161.

Kosaka T (1983b) Neuronal gap junctions in the polymorph layer of the rat dentate gyrus. Brain Res 277:347-351.

Kosaka T, Hama K (1985) Gap junctions between non-pyramidal cell dendrites in the rat hippocampus (CA1 and CA3 regions): a combined Golgi-electron microscopy study. J Comp Neurol 231:150-161.

Kosaka T, Nagatsu I, Wu J-Y, Hama K (1986) Use of high concentration of glutaraldehyde for immunocytochemistry of transmitter-synthesizing enzymes in the central nervous system. Neuroscience 18:975-990.

Kosaka T, Katsumaru H, Hama K, Wu J-Y, Heizmann CW (1987) GABAergic neurons containing the $\mathrm{Ca}^{2+}$-binding protein parvalbumin in the rat hippocampus and dentate gyrus. Brain Res 419:119-130.

Lacaille J-C, Mueller AL, Kunkel DD, Schwartzkroin PA (1987) Local circuit interactions between oriens/alveus interneurons and CA1 pyramidal cells in hippocampal slices: electrophysiology and morphology. J Neurosci 7:1979-1993.

Llinás R, Baker R, Sotelo C (1974) Electrotonic coupling between neurons in cat inferior olive. J Neurophysiol 37:560-571.

McBain CJ, DiChiara TJ, Kauer JA (1994) Activation of metabotropic glutamate receptors differentially affects two classes of hippocampal interneurons and potentiates excitatory synaptic transmission. J Neurosci 14:4433-4445.

Michelson HB, Wong RKS (1994) Synchronization of inhibitory neurons in the guinea-pig hippocampus in vitro. J Physiol (Lond) 477:5-45.

Miles R, Tóth K, Gulyás AI, Hájos N, Freund TF (1996) Differences between somatic and dendritic inhibition in the hippocampus. Neuron $16: 815-823$.

Miltner WHR, Braun C, Arnold M, Witte H, Taub E (1999) Coherence of gamma-band EEG activity as a basis for associative learning. Nature 397:434-436.

Obata K, Kojima N, Nishiye H, Inoue H, Shirao T, Fujita SC, Uchizono K (1987) Four synaptic vesicle-specific proteins: identification by 
monoclonal antibodies and distribution in the nervous tissue and the adrenal medulla. Brain Res 404:169-179.

Obata K, Fukuda T, Konishi S, Ji F-Y, Mitoma H, Kosaka T (1999) Synaptic localization of the 67,000 molecular wt isoform of glutamate decarboxylase and transmitter function of GABA in the mouse cerebellum lacking the 65,000 molecular wt isoform. Neuroscience 93:1475-1482.

Oertel WH, Schmechel DE, Tappaz ML, Kopin IJ (1981) Production of a specific antiserum to rat brain glutamic acid decarboxylase by injection of an antigen-antibody complex. Neuroscience 6:2689-2700.

Pinching AJ, Powell TPS (1971) The neuropil of the glomeruli of the olfactory bulb. J Cell Sci 9:347-377.

Price JL, Powell TPS (1970) The morphology of the granule cells of the olfactory bulb. J Cell Sci 7:91-123.

Rafols JA, Valverde F (1973) The structure of the dorsal lateral geniculate nucleus in the mouse. A Golgi and electron microscopic study. J Comp Neurol 150:303-332.

Rall W, Shepherd GM, Reese TS, Brightman MW (1966) Dendrodendritic synaptic pathway for inhibition in the olfactory bulb. Exp Neurol 14:44-56.

Rodriguez E, George N, Lachaux J-P, Martinerie J, Renault B, Varela FJ (1999) Perception's shadow: long-distance synchronization of human brain activity. Nature 397:430-433.

Sik A, Penttonen M, Ylinen A, Buzsáki G (1995) Hippocampal CA1 interneurons: an in vivo intracellular labeling study. J Neurosci 15:6651-6665.

Singer W, Gray CM (1995) Visual feature integration and temporal correlation hypothesis. Annu Rev Neurosci 18:555-586.

Skinner FK, Zhang L, Perez Velazquez JL, Carllen PL (1999) Bursting in inhibitory interneuronal network: a role for gap-junctional coupling. J Neurophysiol 81:1274-1283.

Sloper JJ (1972) Gap junctions between dendrites in the primate neocortex. Brain Res 44:641-646.

Sloper JJ, Powell TPS (1978) Dendrodendritic and reciprocal synapses in the primate motor cortex. Proc R Soc Lond [Biol] 203:23-38.

Soltesz I, Deschênes M (1993) Low- and high-frequency membrane potential oscillations during theta activity in CA1 and CA3 pyramidal neurons of the rat hippocampus under ketamine-xylazine anesthesia. J Neurophysiol 70:97-116.
Somogyi P, Nunzi MG, Gorio A, Smith AD (1983) A new type of specific interneuron in the monkey hippocampus forming synapses exclusively with the axon initial segments of pyramidal cells. Brain Res 259:37-142.

Sotelo C, Korn H (1978) Morphological correlates of electrical and other interactions through low-resistance pathways between neurons of the vertebrate central nervous system. Int Rev Cytol 55:67-107.

Sotelo C, Llinás R, Baker R (1974) Structural study of inferior olivary nucleus of the cat: morphological correlates of electron coupling. J Neurophysiol 37:541-559.

Steriade M, Contreras D, Amzica F, Timofeev I (1996) Synchronization of fast $(30-40 \mathrm{~Hz})$ spontaneous oscillations in intrathalamic and thalamocortical networks. J Neurosci 16:2788-2808.

Traub RD (1995) Model of synchronized population bursts in electrically coupled interneurons containing active dendritic conductances. J Comput Neurosci 2:283-289.

Traub RD, Miles R (1995) Pyramidal cell-to-inhibitory cell spike transduction explicable by active dendritic conductances in inhibitory cell. J Comput Neurosci 2:291-298.

Traub RD, Whittington MA, Colling SB, Buzsáki G, Jefferys JGR (1996a) Analysis of gamma rhythms in the rat hippocampus in vitro and in vivo. J Physiol (Lond) 493:471-484.

Traub RD, Whittington MA, Stanford IM, Jefferys JGR (1996b) A mechanism for generation of long-range synchronous fast oscillations in the cortex. Nature 383:621-624.

Traub RD, Spruston N, Soltesz I, Konnerth A, Whittington MA, Jefferys JGR (1998) Gamma-frequency oscillations: a neuronal population phenomenon, regulated by synaptic and intrinsic cellular processes, and inducing synaptic plasticity. Prog Neurobiol 55:563-575.

Whittington MA, Traub RD, Jefferys JGR (1995) Synchronized oscillations in interneuron networks driven by metabotropic glutamate receptor activation. Nature 373:612-615.

Ylinen A, Bragin A, Nádasdy Z, Jandó G, Szabó I, Sik A, Buzsáki G (1995) Sharp wave-associated high-frequency oscillation $(200 \mathrm{~Hz})$ in the intact hippocampus: network and intracellular mechanisms. J Neurosci 15:30-46. 